\title{
PROCEEDINGS
}

\section{of $\mathrm{THI}$

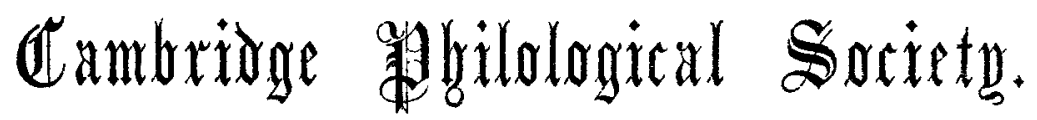

\section{CXXXVI-CXXXVIII.}

\section{LENT, EASTER AND MICHAELMAS \\ TERMS, 1927.}

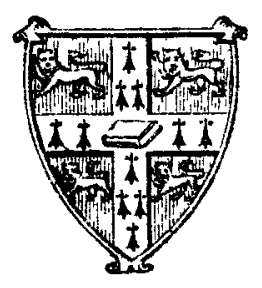

CAMBRIDGE UNIVERSITY PRESS LONDON: FETTER LANE, E.C. 4 1928

(All rights reserved)

Price One Shilling net. 


\title{
Cambrioge 羽ilological まocity
}

\section{COUNCIL FOR 1927}

\author{
Frestiont \\ H. RACKHAM, M.A., Christ's \\ Yice=jugestoents \\ Prof. A. C. PEARson, Litt.D., Trinitx \\ J. R. WARDALE, M.A., Clare \\ D. B. ROBERTSON, M.A., Tninity

\section{Groinary ftemtiers of Council}

PRof. D. J. RAPSON M.A., Sr Johis's Miss J. R. BACON, Grmton

Prof. F. C. BURIITI, D.D., TarNTY

R. D. HICKS, M.A., Trintey

E HARRISON, Mi.A., TrINITY

Prof. F. E. ADCOCK, M.A., Krna's
W. T. VESEY, M.A., CaIde

Peof. A. A. BEVAN, M.A., Trrnity

REx. Prof. A. NAIRNE, D.D., JEsus Miss B. S. PHILLPOTTS, Girmox

A. B. COOK, LrrT.D., QDEEনS'

S. W. GROSE, M.A., Christ's

Zlon. Treasurer

W. H. DUKE, M.A., JESES

79on. Eecretaries

A. D. NOCK, M.A., Clare | C. T. SELTMaN, M.A., Qteens'

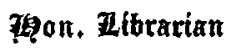

B. L. Hallward, M.A., Peterhouse

Tiqon. Auditors

J. M. EDMONDS, M A., JEste

S. G. CAMPBELL, M.A., CHEIBT's

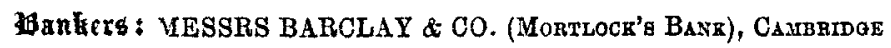

